\title{
Generational Bridges: Supporting Literacy Development With Elder Storytelling and Video Performance
}

\author{
Kathy Snow, Noelle Doucette, and Noline Francis
}

\begin{abstract}
This paper describes our implementation of digital storytelling within a First Nations community elementary school in eastern Canada. Our aim with this project was to support community engagement in the school, while promoting literacy development, by inviting Elders to share their stories, both traditional and modern lived experiences, with children in a grade $4 / 5$ split class. Positioned as a participatory action research project, anchored in Indigenous methodologies, the project was developed through meetings with community members to build on the strengths of the community. Reflections from students illustrate that working with Elders gave deeper meaning to the stories they heard and performed, and fostered greater engagement in literacy development.
\end{abstract}

\section{Background of the Development of Generational Bridges}

In conceptualizing the Generational Bridges project, we came together, as grade 4/5 teacher, education codirector, and outsider researcher, to ask what is the next step for school improvement? Many conversations were held over coffee and tea, in offices and homes, in search of an answer. We began with an accounting of assets, identifying strengths in the community. Potlotek First Nation has a long history of resistance to colonization. The community, and members of the community, refused to move to either of the proposed relocation sites for Mi'kmaq during the 1942 "centralization plan" implementation. Refusal to move meant a loss of services and support promised to the Mi'kmaq through the treaty process. Despite, or perhaps because of, this history, Potlotek is home to many recognized leaders including Lillian Marshall, an accomplished historian and linguist; Noel Doucette, one of the founding members of the Assembly of First Nations (AFN); and first home to Marie Battiste, who is recognized internationally for her work in decolonizing education. The community itself is considered by many as the capital of Mi'kma'ki (the collective Mi'kmaq territory including Nova Scotia, Prince Edward Island, Newfoundland, New Brunswick, and Quebec) because it includes Chapel Island-an island considered sacred by Mi'kmaq. The island has served as a traditional meeting place for the Grand Council of Chiefs since time immemorial and became home to the Feast of St. Ann in the mid-18th century when the French erected a Catholic church on the island. One of the strengths of the community was the elementary school, which is one of the few schools in the province with a full-time land-based learning instructor with dedicated facilities and scheduling for land-based learning at all levels of K-9 instruction. The community radio station, the high school, and the education director's office (parallel to office of the superintendent in mainstream education offerings) are all located within the same building, adjacent to the elementary school. The physical proximity, and small number of people working in these 
locations, leads to collaboration and synergies in activities. The small number of students, and the welcoming, family approach to relationships in school, lead to a great deal of team teaching, shared resourcing, and a blurring of the boundaries of formal and informal learning.

In further discussions, it was determined there were also clear directions the community wanted to grow. The staff and director of the radio station had been involved in supporting media skills development through youth internships and writers' workshops with a focus on creating short journalistic pieces. When we asked the radio station director what his vision was for further development, he identified the need to build on the workshop programming with a broader audience. Noelle, then education codirector, was concerned about community engagement in the school. She, as well as the elementary school principal, noted that parents and families were not as frequent visitors to the school as they had hoped. At the same time, the grade 4/5 classroom teacher was seeking methods to differentiate literacy instruction through culturally relevant project-based learning. Through these discussions the natural starting point appeared to be storytelling, as a culturally responsive pedagogy supporting literacy development. Bringing all of these discussions together, we sought to bridge generations by combining traditional and modern techniques to support knowledge sharing and to engage both parents/Elders in learning.

This project became an act of decolonization, as we attempted to design a project based in Etuaptmumk (two-eyed seeing) — a theoretical and practical construct for designing learning by Elders Albert and Murdena Marshall. Albert Marshall explains this concept on his integrated science website as the ability to:

learn to see from your one eye with the best or the strengths in the Indigenous knowledges and ways of knowing .... and learn to see from your other eye with the best or the strengths in the mainstream (Western or Eurocentric) knowledges and ways of knowing ... but most importantly, learn to see with both these eyes together, for the benefit of all. (n.d.)

\section{Literacy Development}

\section{Traditional Storytelling as a Pedagogy}

We adopted an assets-based stance, presuming that challenges to literacy, attendance, engagement, and behavior were based in historic injustice and systemic bias, rather than deficits possessed by the children, their parents, or the community. At the foundation of the research was the belief that local and Indigenous control of education leads to more relevant, and thus more effective, learning and higher levels of student success (Agbo, 2002). In Nova Scotia, this concept has been illustrated by the rise of Mi'kmaq students' graduation rates to $91 \%$ during 2017-18 surpassing non-Mi'kmaq students in the province and significantly higher than the national average (35\%) since the inception of the Mi'kmaw Kina'matnewey (MK), an educational collaboration of 12 of the 13 Mi'kmaw bands in Nova Scotia (MK, 2018; Simon, 2014). Curriculum resources seated in Mi'kmaw tradition and values have been slower to follow, but are continually being developed, and Mi'kmaq educators and schools must also decolonize themselves to move away from the Eurocentric teachings forced upon them through historic processes and ongoing 
accreditation systems. Indigenous children have not been well served by current approaches to literacy development (Hare, 2011). As an example from Nova Scotia, although 41\% of Mi'kmaw grade 6 students completing the provincial literacy assessment scored a level 3 (basic pass standard) or above, when the average was deconstructed into the various skill components, approximately $15 \%$ of these "passing" students scored below the pass level in the area of "organization, language use and conventions of reading and writing" (MK, 2018). Indicating that although students are performing well in speaking and listening within the areas of reading and writing, more can be done to support the students. However, the discrepancy between Mi'kmaw and mainstream literacy success needs to address that formal literacy assessments also ask children to adapt to colonial ways of thinking and communicating to succeed.

According to Iseke (2013), storytelling is a practice in Indigenous cultures that sustains communities, validates experiences, nurtures relationships and the sharing of knowledge. Telling, understanding, and retelling a story is a highly valued literacy. Lowan-Trudeau (2015) explains the power of storytelling as pedagogy is that it is highly adaptable- the story can be modified to suit the current lives of the audience without changing the original meaning and values, which allows the audience to better relate to the concepts of the story. Battiste (2011) outlines storytelling and the role of Indigenous language use in the telling of the story as giving unconscious order and structure to understanding. From a mainstream perspective, educational theorists such as Dewey (1934) and Vygotsky (1978) also value storytelling in learning, as a means to creating lasting impressions, deep learning, and interconnections among learners. Extending storytelling through digital media, Powell, Weems, and Owle (2007) state that through interpretation with technology enhancements, digital stories offer a way Indigenous students can move beyond paper-and-pencil responses to creative representation that supports identity development and decolonizing practices in education.

\section{Digital Story Creation}

Indigenous digital storytelling provides opportunities for Indigenous peoples to change the dominant narrative. Through self-representations that challenge the taken-for-granted and stereotypical (mis)representations frequently presented in mainstream society, digital storytellers create lasting products that better reflect culture and beliefs (Iseke-Barnes \& Sakai, 2003). This is a contrast to the recording of Indigenous storytellers as "artefacts" by mainstream researchers as an ethnographic examination tool, which has been criticized as not a true expression of culture (Manuelito, 2015). The creation of the digital stories for this project was positioned as an artistic expression by the students and the Elder storytellers who created them. Raheja (2011) identified creative self-representation in media as a form of visual sovereignty, or the right of a group to depict themselves with their own values and goals as central. Therefore, Indigenous digital storytelling also creates opportunities to understand political activism and creates spaces for Indigenous youth to affirm their identity and become agents of social change (Pratt, 2010). Returning to academic development, Skinner and Hagood (2008) have outlined the role of digital storytelling to promote language learning for second-language learners by supporting foundational literacy skills, new digital literacies, and self-esteem. The importance of self-esteem in early elementary literacy development has been well documented (Boyes, Tebutt, Preece, 
\& Badcock, 2018; Koosha, Abdollahi, \& Karimi, 2016). Self-esteem has been found to be fostered in partnership with holistic learning when it involved working with Elders (Castellano, 2004).

\section{Elders as Teachers}

Parent and Elder involvement in schools is most frequently associated with supporting programs external to learning, such as donating items for the classroom, attending concerts, parent-teacher interviews, and classroom management support (Pushor \& Murphy, 2004). Commonly, conversation between parents and teachers may be limited to discussing academic and behavioural challenges observed in the classroom (Pushor \& Murphy, 2010). And in the case of Indigenous people in Canada, relationships between formalized school, teachers, and even the physical building, can be loaded with trauma based on the history of residential schools leading to avoidance of the institution. Bringing parents and Elders into the school as equal and valued members of the community is important to begin restorative practices related to education. Hare (2011) cautions that when educational messaging at school is presented in a dramatically different way than expressed at home, children are not as successful. Therefore, it is important to develop a shared process for learning that includes Elders, traditional values, ways of learning, and language in ways that move beyond colonial approaches to educational development. For example, great success in language restoration has been observed through the adoption of language nests which inherently involve all community members in learning (Pitawanakwat, 2008).

\section{Methodology}

This participatory action research (Finley, 2008; Gillis \& Jackson, 2002; Whitehead \& McNiff, 2006) was anchored in Indigenous methodologies that prioritized relationship, dialogue, and respect (Kovach, 2009; Smith, 1999). Our choices were informed by mutual respect and First Nations statements about appropriate and desirable researcher conduct with First Nations communities (Battiste, 2011; LowenTrudeau, 2012). We were respectful of different forms of knowledge and existing expertise in Mi'kma'ki, drawing on the strengths of academic and Elders advising the design of the classroom activity. Methods of data collection included observation of students in the classroom, a short debriefing conversation (Healey \& Tagak, 2014; Kovach, 2010). The debrief with the children consisted of five questions and each one-to-one interview was approximately 5-20 minutes depending on the child's response. Two longer discussions with the classroom teacher were held and focused on her observations of the impact of the activity and its design. Principles and procedures for protecting anonymity or giving due credit (naming participants) was negotiated with adult participants as per their preference. Before commencing any work within the school, ethics approval was obtained from the university research ethics board, the Mi'kmaw Ethics Watch Committee, and the Potlotek Band Chief and Council. 


\section{A Path to Relationship Building}

Our first attempt to conduct the project occurred in the spring term of the 2017-2018 school year. The teacher of the $4 / 5$ class sought to gain parent, grandparent, and Elder volunteers to participate in the project. The invitation was sent out in paper handouts through the students, emails to parents, and open calls on the School Facebook page, and resulted in no volunteers coming forward. In retrospect, this was not surprising given the intention of Elder engagement was to respond to the desire to increase parental engagement in the school. Noelle explained that community members, and Mi'kmaq in general, are very humble and very shy. There are a few outgoing individuals in each community, and these people often have busy careers or are called to many activities. Frequently, adults in community don't realize the fountain of knowledge they have to share with youth and others. Noelle was concerned that we were missing a vast collection of stories and historical knowledge, which was another reason for a project of this type, to empower the community members to recognize and share their voices. As an outside researcher, though Kathy had built some relationships within the school and community, the community was rightfully skeptical about her intentions and what she was doing there. With school ending for the summer, we left the project open to begin again in the fall. However, the fall saw many changes. Both the principal and teacher of the $4 / 5$ class left their positions. Noelle facilitated introductions with the new teacher and the principal as we sought to explain our project and determine if it was still relevant.

In the fall of 2018-2019, Noline, the new grade 4/5 teacher, sent out an open call for participation. This time we were successful in receiving volunteers. Unfortunately, scheduling challenges led to difficulties getting started with our volunteers. Noelle, not easily discouraged, pointed us in a new direction. Several years before, Lilian Marshall, one of the Elders in the community, had been involved in the creation of a picture book from the traditional story "Muin and the Seven Bird Hunters." Community members had adapted the story into a theater performance that the grade 4/5 class was preparing to perform as part of the local Celtic Colours festival. Noelle suggested we record the performance, and work with this recording in the classroom so the children could learn how to edit, write, interpret, and work with video. Noline and Kathy taught the children how to combine video clips, add subtitles and transitions to produce a completed story using iPads loaned to the project from the Centre for Sound Communities, a research institute within the local university. The children were highly engaged in the project and enjoyed watching and sharing the videos they created. Now that we had an example of the product, we reached out a third time for community storytellers. Two storytellers came forward, both with close ties to the education department: George Marshall, the director of the radio station, and Nora Bernard, an Elder in residence with the school.

\section{The Project Implementation}

Schools are busy places, and what was planned as a two-week activity with the children was extended to three months. Rather than a two-week intensive activity, the project was completed in phases around the other activities of the school. The project would not have been completed without the dedicated support and flexibility of programming provided by the school administration. Initially, we established a 
series of classroom "Tea With Elders" times. In total, three of these sessions took place. During Tea With Elders, the volunteer Elder storytellers visited the classroom and were served tea and cookies by the children. The class consisted of nine children and was divided into two groups. Each group was responsible for getting to know and take care of their Elder storyteller, who they quickly began referring to as "our Elder." The initial meeting was simply introductions and time for getting to know one another. This time for relationship building by adopting traditional protocols established a space for the stories to be shared that was reflective of the traditional storytelling process and important to respecting the cultural storytelling space (Iseke, 2011). In the second session, children heard a story shared by the Elder and were given time to ask questions. There was a great deal of laughter during these sessions as children connected with the Elder and made connections between their own experiences, shared relatives, and the story. Noelle explained laughter is also important to Mi'kmaq learning traditions and her claim has been supported by the work of Manuelito (2015) in discussions of creating space for Indigenous digital storytelling. During the third session, children created storyboards, with each child choosing an aspect of the story and drawing an interpretation, as well as writing text to accompany the story. Children needed to work with one another, negotiating the selected part of the story and how it would be portrayed with the others in the group. Elders reviewed the childrens' interpretations of the story, corrected misinterpretations, made suggestions for illustrating backgrounds and future performances, described the place where the story occurred, and added more details that may have been missed in the initial telling. Both Elders chose to share modern stories, rather than traditional or more sacred stories. Stories were chosen because they were short and easy to share. The stories offered insights into traditional values, but were highly relatable. The children could recognize the people in the stories, the locations and events. The stories also offered a view of the Elders' early lives, sharing not only aspects of the personal history of the Elders, but also that of community activities and events.

The format of the stories shared by the Elders was different. Nora's story was a personal account of a visit to her aunt's house and the walk home, while George's story was read from a booklet produced by his aunt. George's, or rather his aunt Lillian's, story, told the story of her experiences on a culturally significant day in the community. The booklet was helpful for some students in visualizing the story and providing a model for writing. The lack of formalized documentation of Nora's story led more conversations around interpretation and writing. Both approaches offered benefits to the children for different reasons: the scaffolding provided by the booklet was motivating for some children who found writing more challenging, while the open space for creative interpretation was motivating for others. 


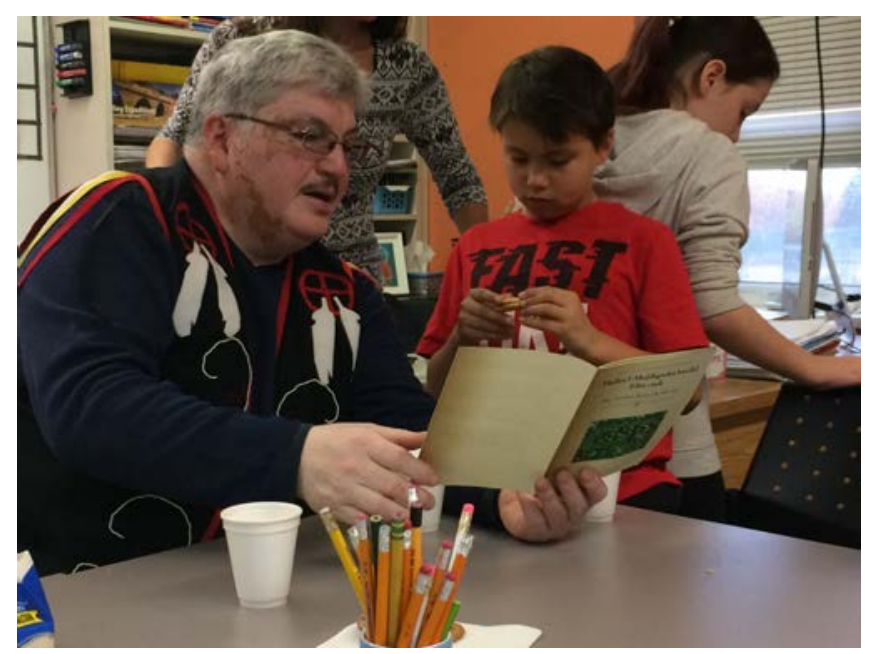

Fig. 1: Storyteller George Marshall shares a story written by his Aunt Lillian Marshall with one of the children in his group.

Once the storyboards were ready, the children travelled to the university with their storyteller to perform the story in front of a green screen. Though we had originally planned to do this in the community, we later decided that a trip to the university would offer a full day of uninterrupted filming time and also be exciting for the students. Performance parts were created for all of the children, which meant some aspects of the original stories were modified through discussions with the storytellers during the day. The Elders acted as directors for the performance, guiding the children in their expressions of emotions, actions, and portrayal of the story. While one group was filming, the second group of children was creating the images that would be used for the background on the green screen using a simple drawing program on the iPads.

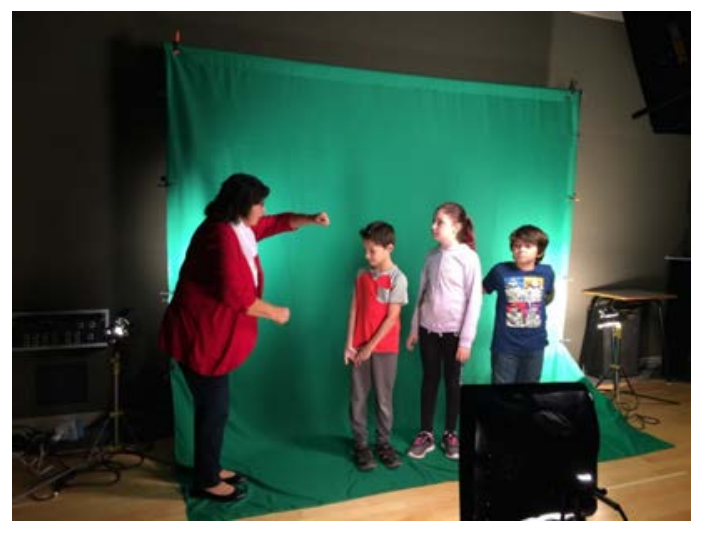

Fig. 2: Storyteller Nora Bernard directs the action for the video of her story.

It was originally hoped the high school students would work with the radio station through their internships or a volunteer club to learn the technical skills to merge the children's animated images into the green-screen-captured video. Because of time delays, the high school students were no longer available, so two radio station staff (the director and a community staff member) did this work. Nora's group asked to have their original storyboard drawings from pen and paper included in the video because they were very proud of their images. George's group used digital drawings made on iPads, specifically 
as backgrounds for the green screen after the performance. In both cases, the images were added and enhanced with animation by the tech team when the videos were edited and compiled.

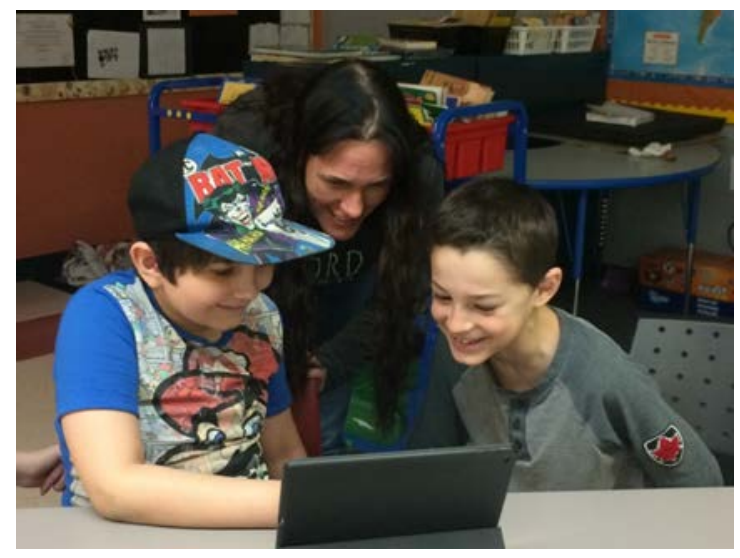

Fig. 3: Noline works with her students to edit the video and create subtitles.

The draft videos were returned to the classroom for the children to provide feedback. The process of editing was explained, in relation to the work the children had previously done with the "Muin" video. The children began to add subtitles, an opening/title sequence, animation, as well as closing credits. These changes were compiled, and the original Elder storytellers reviewed the videos with the children to clarify language. The school has the benefit of a formal "Land-based learning teacher" who is also identified formally as an Elder in the community. The land-based teacher visited with the children and their Elders during this review and added, from his position of authority, further feedback. This process of consensus building, through gathering and sharing interpretations of the story, not only served to ensure the accurate representation of the story, but also the Mi'kmaq values of decision making and honoring accuracy in story. As a direct example, we share a critical discussion which emerged from differing interpretations and approaches to problem solving. During filming, an additional brother was added to Nora's story so that all children would have a performance role. Though not the truth, this modification of the story was considered acceptable to ensure inclusion of all children. However, also modified during the performance, it was decided that both brothers mirror Nora's activities, to increase their presence on screen. It was decided that little brothers copying their big sister would offer additional humour to the story. However, in the revision of the narrative for the changes which arose on filming day, the boys were initially referred to as "naughty brothers, who liked to tease their sister." Upon seeing this, Nora wanted changes made. She did not want to refer to any children as naughty in the film. Nora didn't want the parents of the "naughty boys" to see them called naughty on screen; furthermore, she felt this was not an accurate perception of their actions. Nora's interpretation of the addition was that the boys were not naughty, but instead playful. This counternarrative was important to defining relationships, where children's playful behaviour in the classroom can be viewed as naughty and punishable. These insights from Nora likely offered greater impact to the researchers and teacher than they did to the children, but illustrate where cultural bias in language and interpretations of actions can lead to conflict. Nora's comments illustrate the role of defining relationship patterns through storytelling, and how a discussion of these patterns can play an important role in defining interactions in the 
classroom. What might be observed as "misbehaving" by a teacher, or even fellow students, is recast through Nora's story as playfulness and a valued characteristic, which, in turn, changes teacher and fellow student response. Though the duration of the project was too short to make definitive claims to a changed student-teacher relationship, and the current teacher already illustrated a consensus building approach to classroom management, it was observed that the conversations around behaviours and discussions about how to position the "naughty boys" served as social stories that supported a more positive classroom environment. The addition of the land-based learning teacher, an Elder, who offered a critical lens to language usage, deepened dialogue and discussion on culturally relevant interpretations further. In the case of Nora's story, some words were not translated to English within the story, because the Mi'kmaq words were more relevant and offered a specific meaning that was reflective of culture, that could be lost in translation. To ensure the profile if $\mathrm{Mi}^{\prime} \mathrm{kmaq}$ remained prominent, the land-based teacher suggested that subtitles in $\mathrm{Mi}^{\prime}$ kmaq should be added not only to the Mi'kmaq narration, but to the English narration as well. The process of adding Mi'kmaq in written form allowed us to revisit language and translation. We took the videos to the language teacher from the high school, as well as a language expert in the community, and through another process of consensus decision making, they revised the narration and provided an accurate translation into Mi'kmaq. Beyond simply developing an accurate translation, the process of developing the translation engaged more community members in the project. This dialogue included a teaching for the children about the process of translation and meaning making across two language groups with different grammatical and cultural bases. The videos were brought back to the classroom for the children to view and a celebration with the community was planned.

The official launch of the videos occurred in June at an annual information session for the community on the activities of the school. The children were bussed to the community center, the entire community was invited, and a feast was held. The teacher introduced the project and its aims, the videos were shown, and each of the children spoke about the project in both English and Mi'kmaq. Many parents attended. It was evident from the children's smiles they were pleased with their creations. The parents appeared to be happy as well, everyone laughed at the jokes in the videos, and the presentation felt like a celebration of success. However, our observations of success are an incomplete picture of the impact on the children.

\section{Reflections From the Children}

Six of the nine participating children agreed and received parental permission to be interviewed and speak to us about the project. From these six children, important insights about the role of Elders stories and performance in storytelling arise and point to the importance of both of these activities for literacy development.

\section{Stories Have Meaning and Context}

The children connected words on a page, written language, to meaning and context. In the words of one child, "I learned that stories are more than just words," while another stated, "I learned that stories teach us about our past." The importance of these simple statements from the students cannot be 
underestimated, particularly in this context, where children are commonly presented with mainstream (non-Indigenous) reading materials that lack cultural relevance. In other words, stories are frequently "just words" on a page without meaning or relevance. One of the critical developments within reading comprehension is to develop an understanding and appreciation of text (Veenendaal, Groen, \& Verhoeven, 2015), and through oral tradition, engagement with Elders, and performance, students were able to make this connection. Namely, the children learned that stories and storytelling (told, written, performed, recorded) are powerful tools for remembering history, in sharing cultural knowledge, and in communicating what was known.

\section{Listening to Elders Is Important}

All of the students identified the importance of listening to Elders and enjoyed learning from them. Research has shown that to develop fluency, students need to: hear and use spoken language in many contexts, and engage in discussions where they use language for meaningful communicative purposes (Graves, August, \& Mancilla-Martinez, 2012). The children built relationships with the Elders, as one child stated, "I learned that Elders are funny," and another said, "I learned that Elder stories are important," continuing with "it's like a piece of history, if the Elder passes without sharing the story then no one else will be able to pass it on." Children learned to listen carefully, to talk to an Elder for advice, and that Elders stories carry important messages about how to interact with the world. Another student inverted the message, stating that, "Elders care about their stories," but followed up explaining that they believed the Elder's interpretation, that stories are important. Students learned it is important to ask questions, and to check for understanding. Literacy-focused research further evidences that oral language activities in the classroom are critical for students' reading comprehension (Martin-Beltran, Tigert, Peercy, \& Silverman, 2017). The opportunity to work in small groups, and with one-to-one interactions with their storyteller, allowed the students to develop interpretation and question asking skills in a safe and supportive environment, that may support their literacy development in future.

\section{Interpreting Stories}

Returning to Vygotsky and social constructivism, the role of dialogue has been outlined as enhancing student thinking and literacy development (Wilson, Fang, Rollins, \& Valadez, 2016). Beyond ensuring that understanding of the story was correct, the students spoke about learning to: create the video, check that the parts of the story worked together smoothly, and confirm the interpretation and sequencing was accurate and clear. For example, one student identified the need to learn how to "space out" the images, words, and titles to ensure that the narration and subtitles matched and were easy to read. Another student mentioned, "I get stuck on some words," but followed by saying the performance assisted in the understanding and review of words. While another student mentioned, "I really liked drawing the lanterns," referring to creating the illustrations for the story, and learning what a lantern was and what it looked like based on the Elders feedback. Accuracy of storytelling and representation of interpretations is a critical aspect of Indigenous storytelling approaches, so not only did dialogue and interpretation through this project support mainstream literacy development, but it also supported the development of 
culturally specific values in relation to storytelling. When asked, "how do you prefer to learn, with an Elder or with a book?" one student outlined, "working face-to-face with an Elder is easier and more fun, you can't chat and share tea with a book, you can't ask a book questions." In addition, through the storyboard, performance, and video finalization process, children, in discussion with Elders, learned when and where modifications to stories can be respectfully made to balance accuracy against creativity. In another example, one child explicitly named values she learned from the story: "I learned how to ask my parents politely to go visiting," which was presented in the content of Nora's story.

\section{Reflections From Activity Design}

In listening to the children's interviews and our own reflections on the value of the project, all participants, teachers, Elders, and researchers agreed that our project should be repeated. We observed that the activity added value not only for literacy development and technology skills, but also for the holistic development of the children.

\section{Relationship Building With Elders}

New relationships were formed between the students and both storytellers through the project, regardless of group membership. Students learned about the lives of the storytellers and grew their community support network. Archibald (2008) evidences the importance that Elders stories have on holistic learning and development for children in elementary school. The benefit of mentoring and external support networks for student retention and resilience has been documented for Indigenous students entering postsecondary (Gallop \& Bastien, 2016; Snow, 2017), but little has been documented in relation to public education. We propose that waiting until postsecondary to consider support networks is too late, and these should be fostered early in children's academic lives, so that relationships are well developed prior to increasing pressures and demands of study. Furthermore, Pidgeon (2008) outlines that persistence is supported by self-efficacy through finding personal talents, maintaining cultural identity and reciprocity through service to community. Through the open design of the activity and the prolonged contact with storytellers, students were able to deepen their relationships with these key members of the community. We hope these relationships will support them as they continue to progress through education. In speaking about the Elder experience, one student stated, "working with Elders is fun, I have a Grandpa and he and I hang out all the time, share some tea, hot chocolate, cookies and chat about stuff." While a second student replying to the question, what did you learn from this project?, answered, "Elders are interesting and fascinating!" In addition, the Elders, as kind grandparent-like models, supported the children in their learning about themselves, their culture, and their community. The Elders provided far more depth of understanding of, "who am I and where I come from," than could be provided through reading alone. Reading, telling stories, and being exposed a diverse typology of literature are consistent goals in the classroom. Finding ways for children to make personal connections to texts is a significant challenge. However, building relationships and personal interactions with Elders created foundations for establishing those personally relevant connections before the storytelling even began. 


\section{Performance and Literacy_-Interpretation and Engagement}

The performance was identified by most of the children as their favourite aspect of the project. As an example, one student stated, "My dad is a writer, he writes songs and plays and it [the project] inspired me to do the same stuff, it is interesting and cool once you get into it. I really had fun with it." Another student outlined the ability to play and laugh during the performance as the most interesting part of the project, saying, "in our video, my face was hilarious." Though children did not discuss this explicitly, teachers and researchers observed that performance, and the correction of interpretation through performance, was important for understanding. Two children explicitly stated the direction offered by the storyteller helped them to understand the meaning of the story, as exemplified by this comment: "a few times we had to do it again [the performance] to get it right based on the story." The class was considered "busy", with several children presenting with challenging behaviours. Very few and always minor behavioural incidents occurred during the creation of the videos. Through active learning and performance, children were highly engaged. The need for an additional actor (a parent figure in one story) allowed us to engage an older student (on a highly individualized learning plan) who became a supported and active learning member within the group. Students engaged with storytellers through questions. They were independently motivated to clarify details and seek understanding to improve their portrayal of the story in the video. Children were further motivated, through the processes that followed, to visualize the story, recall and sequence main events, and attend to and clarify details. Student re-creations demanded high order critical and creative thinking, problem solving, identifying, recognizing and working with literary elements, characters, dialogue, and setting. The final product became a source of great pride for students, a pride they shared with their now Elder friends, their parents, and their community.
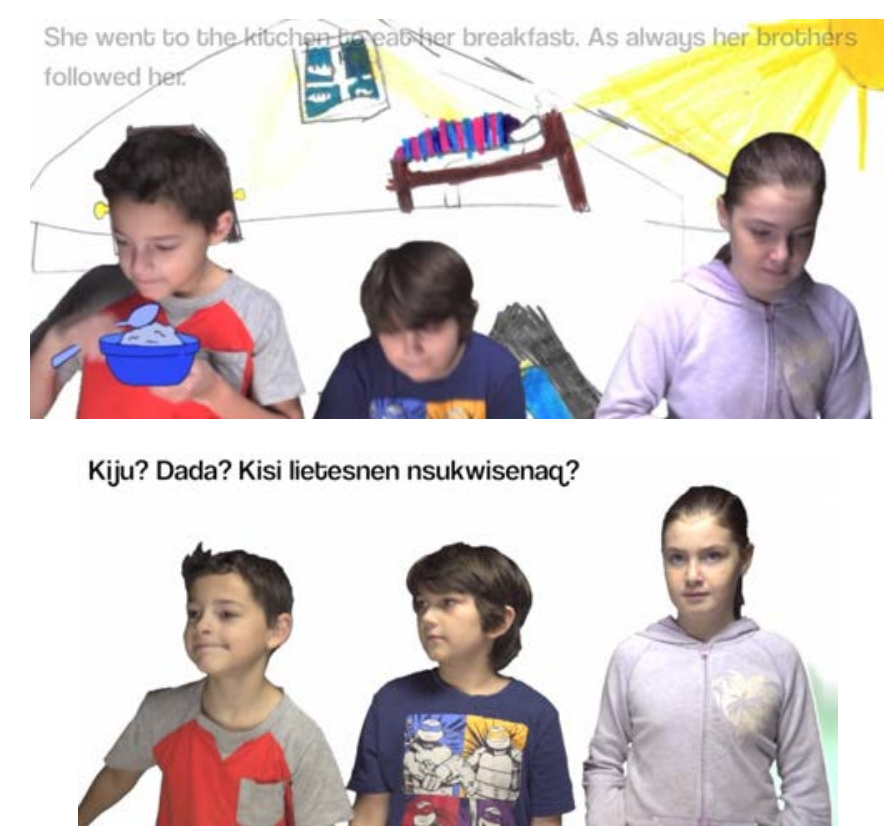

Fig. 5: Sample images from the completed video entitled, "Nora's Story," illustrating the students' animation and subtitles in Mi'kmaq and English. 


\section{Collaborative Learning_Differentiated Instruction and Peer Support}

Literacy levels were highly diverse within the class. The act of performance, collaborative interpretation through shared storyboarding, and discussions between peers and storytellers, allowed for an array of differentiation strategies to support learning. As mentioned previously, the scaffolding provided by the booklet served as an additional differentiation strategy. The shared purpose of creating a high-quality product for the community, rather than a focus on individual progression, was effective in reducing stigma associated with skill level. The one-to-one support from classmates, Elders, teacher, and teachers aid during the group-writing events provided in-class differentiation without the stigma of "pull out support" or "individual education plan" tools. The children worked as a team with "their Elder" to make the best quality production they could. Noelle observed, "It's always a treat to see students thoroughly engaged without feeling like it's classroom work. Mi'kmaq are hands-on learners and the students really thrive in this type of environment." With the goal of the product in mind, corrections of interpretation and writing were easily accepted by students. Alternatively, the teacher observed that grades and teacher comments on writing can result in demotivation and withdrawal from the writing process. One child stated working with the Elders and her classmates in this way helped improve her vocabulary because she could discuss the meaning of new words. With the external shared goal of collaborative performance, and digital story production, competition between students (the evaluation of self in relation to others) was reduced. Each child participated fully within the group and shared pride in the final product. In the words of one student: "the project was hard, but worth it."

\section{Concluding Thoughts}

Though the project was not completed as planned, many of the challenges became opportunities for student learning. The prolonged engagement with storytellers allowed for deeper relationship building and more open feedback and sharing. Children strengthened their ties to storyteller role models. Though we had hoped to work in smaller groups (two to three children per storyteller), the larger collaborations of four and five children per storyteller created more dialogue and discussion than would have been observed in our original planning. The dialogue around the stories, their meanings, and how they should be presented created an environment for deep learning to occur. And the learning was bidirectional, between the researchers, teachers, Elders, and students. Through the lens of Etuaptmumk, values and interpretations were recognized, discussed, and challenged, to lead to greater understanding, or a binocular vision related to a possibility of multiple interpretations. The learning was not only related to mainstream values of literacy development, but also inherently included cultural values around storytelling. The stories, which included locations and people the children were familiar with, was highly motivating; students could build on their own knowledge of places and people and extend the stories by asking clarification questions. Furthermore, literacy development of both English and Mi'kmaq occurred concurrently within the creation of the stories as the children navigated the storytellers' use of language, wrote scripts, and revised work. Finally, the ability to move, to rehearse, to gain feedback on dramatizations and to share the final performance offered a physical and mental space to engage with stories that would not have been possible through reading and writing alone. The performance provided 
multimodal engagement in literacy that supported differentiated learning and engagement. If given the opportunity to complete the project again, we would change several things:

a) We would plan from the outset a longer period for engagement with the stories and their tellers.

b) We would increase invitations to the community and engage more "experts," such as fluent speakers of Mi'kmaq and parents earlier in the project, rather than at the end.

We would film the performance at the school, to reduce the pressure to complete the filming in one day. The reduced time pressure would allow for more rehearsal and revisioning of the performance, but also ensure children realize this activity is something they can do in their own community. Staying home might also reduce the intimidation some of the children felt while filming at the university.

\section{References}

Agbo, S. (2002). Decentralization of First Nations education in Canada: Perspectives on ideals and realities of Indian control of Indian education. Interchange, 33(3).

doi:http://dx.doi.org/10.1023/A:1020945418910

Archibald, J. (2008). Indigenous storywork: Educating the heart, mind, body, and spirit. UBC Press.

Battiste, M. (2011). Cognitive imperialism and decolonizing research: Modes of transformation.

In C. Reilly, V. Russell, L. K. Chehayl, \& M. McDermott (Eds.), Surveying borders, boundaries, and contested spaces in curriculum and pedagogy (pp. xv-xxviii). Information Age Publishing.

Boyes, M., Tebutt, B., Preece, K., \& Badcock, N. (2018). Relationships between reading ability and child mental health: Moderating effects of self-esteem. Australian Psychologist, 53(2).

doi:10.1111/ap.12281.

Castellano, M.B. (2004). Ethics of Aboriginal research. Journal of Aboriginal Health, 1(1), 98-114.

Dewey, J. (1934). Art as experience. The Barnes Foundation Press.

Finley, S. (2008). Community-based research. In L. Given (Ed.), The Sage encyclopedia of qualitative research methods (pp. 98-101). Sage.

Gallop, C.J., \& Bastien, N. (2016). Supporting success: Aboriginal students in higher education.

Canadian Journal of Higher Education 46(2), 206-224. Retrieved from

http://journals.sfu.ca/cjhe/index.php/cjhe/article/view/184772.

Gillis, A., \& Jackson, W. (2002). Research methods for nurses: Methods and interpretation. F.A. Davis Company.

Graves, M.F., August, D., \& Mancilla-Martinez, J. (2012). Teaching vocabulary to English language learners. Teachers College Press.

Hare, J. (2011). They tell a story and there's meaning behind that story: Indigenous knowledge and young indigenous children's literacy learning. Journal of Early Childhood Literacy, 12(4), 389-414. doi:10.1177/1468798411417378. 
Healey, G., \& Tagak, A. (2014). PILIRIQATIGIINNIQ 'Working in a collaborative way for the common good': A perspective on the space where health research methodology and Inuit epistemology come together. International Journal of Critical Indigenous Studies, 7(1), 1-8.

Iseke, J. (2013). Indigenous storytelling as research. International Review of Qualitative Research, 6(4), 559-577. doi:10.1525/irqr.2013.6.4.559.

Iseke-Barnes, J., \& Sakai, C. (2003). Indigenous knowledges, Representations of Indigenous Peoples on the internet, and pedagogies in a case study in education: Questioning using the web to teach about Indigenous Peoples. Journal of Educational Thought, 37(2), 197-232.

Koosha, M., Abdollahi, A., \& Karimi, F. (2016). The relationship among EFL learners' self-esteem, autonomy and reading comprehension. Theory and Practice in Language Studies, 6(10), 68-78. doi:http://dx.doi.org/10.17507/tpls.0601.09.

Kovach, M. (2010). Conversation method in Indigenous research. First Peoples Child \& Family Review, 5(1), 40-48.

Lowan-Trudeau, G. (2015). From bricolage to métissage: (Re)thinking intercultural approaches to Indigenous environmental education and research. Peter Lang.

Manuelito, B.K. (2015). Creating space for an Indigenous approach to digital storytelling: "Living breath" of survivance within an Anishinaabe community in northern Michigan. Unpublished Masters Dissertation, Antioch University.

Marshall, A. (n.d.). Integrative Science. Retrieved from

http://www.integrativescience.ca/Principles/TwoEyedSeeing/

Martin-Beltran, M., Tigert, J.M., Peercy, M.M., \& Silverman, R.D. (2017). Using digital texts vs. paper texts to read together: insights into engagement and mediation of literacy practices among linguistically diverse students. International Journal of Educational Research, 82(2017), 135-146. doi:https://doi.org/10.1016/j.ijer.2017.01.009

Mi'kmaw Kina'matnewey (MK). (2018). Annual Report 2017-2018 Draft. Retrieved from http://kinu.ca/sites/default/files/doc/2014/Feb/mk_annual_report_2018_draft_1_oct_18.pdf

Pidgeon, M. (2008). Pushing against the margins: Indigenous theorizing of "success" and retention in higher education. Journal of College Student Retention: Research, Theory \& Practice, 10(3), 339-360.

Pitawanakwat, B. (2008). Bimaadziwin oodenaang: A pathway to urban Nishnaabe resurgence. In L. Simpson (Ed.), Lighting the eighth fire: The liberation, resurgence, and protection of Indigenous Nations (pp. 161-173). Arbeiter Ring.

Powell, T., Weems, W., \& Owle, F. (2007). Native/American digital storytelling: Situating the Cherokee oral tradition within American literary history. Literature Compass, 4(1). doi:10.1111/j.1741-

4113.2006.00376.x

Pratt, P.Y. (2010). Taking a stance: Aboriginal media research as an act of empowerment.

In B. Hafsteinsson \& M. Bredin (Eds.), Indigenous screen cultures in Canada (pp. 163-182).

University of Manitoba Press.

Pushor, D., \& Murphy, B. (2004). Parent marginalization, marginalized parents: Creating a place for parents on the school landscape. The Alberta Journal of Educational Research, 50(3), 221-235. 
Pushor, D., \& Murphy, B. (2010). Schools as protectorates: Stories two Mi'kmaq mothers tell. Canadian Journal of Educational Administration and Policy, 112(December).

Raheja, M.H. (2011). Engaged resistance: American Indian art, literature and film from Alcatraz to the NMAI. University of Texas Press.

Simon, L (2014). Mi'kmaw Kina'matnewey supporting student success. Retrieved from https://indspire.ca/wp-content/uploads/2016/09/indspire-nurturing-capacity-mk-2014-en-v2.pdf

Skinner, E., \& Hagood, M. (2008). Developing literature identities with English language learners through digital storytelling. The Reading Matrix, 8(2), 12-38.

Smith, L. (1999). Decolonizing methodologies: Research and Indigenous peoples. Zed Books.

Snow, K. (2017). And still they persisted: A discussion of Indigenous students perspectives on a year in a Pre-Nursing Transitions Program. International Journal of Learning, Teaching and Educational Research, 16(10), 114-131. doi:https://doi.org/10.26803/ijlter.16.10.9

Veenendaal, N., Groen, M.A., \& Verhoeven, L. (2015). What oral test reading fluency can reveal about reading comprehension. Journal of Research in Reading, 38(3), 213-225. doi:10.1111/14679817.12024

Vygotsky, L. S. (1978). Mind in society: The development of higher psychological processes. Harvard University Press.

Whitehead, J., \& McNiff, J. (2006). Action research living theory. Sage.

Wilson, J., Fang, C., Rollins, J., \& Valadez, D. (2016). An urgent challenge: Enhancing academic speaking opportunities for English learners. Multicultural Education, 23(2), 52-54. 


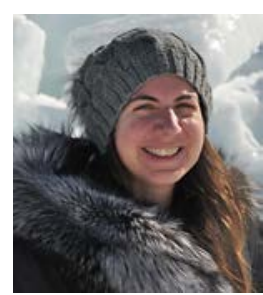

Kathy Snow is an Associate Professor in the Faculty of Education at the University of Prince Edward Island. She is also the academic lead for the Certificate in Educational Leadership Nunavut, which has been designed to provide qualifying educators in Nunavut with the history, knowledge, skills, and attitudes to provide culturally responsive leadership in schools. With her research she explores systemic challenges to supporting Indigenous student success and persistence.

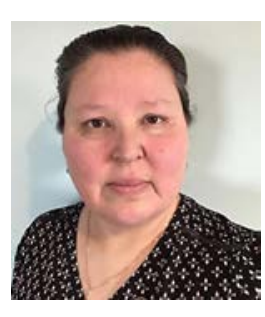

Noelle Doucette is the new Culture and Community Coordinator in Potlotek First Nation, but at the time this project was conducted she was serving her community in the role as Educational Codirector. She is actively engaged in community outreach and has accepted numerous awards on behalf of her community for projects initiated within her office related to public education. She is a board member for the Cape Breton Centre for Craft and Design, Cape Breton Local Immigration Partnership, and multiple committees in her community. Her creative and educational creations include: Potlotek Red Dress exhibit, traditional 18th century Mi'kmaw dress for Fortress Louisburg, Celtic Color Activities, and two Lumiere (art at night) performances (2018 and 2019).

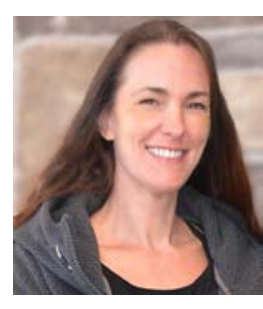

Noline Francis is teacher at Potlotek Mi'kmawey School. She has been teaching for 16 years. She has a Bachelor of Arts with Honours in English literature and a Bachelor of Education from St. Francis Xavier University. Trained in elementary and secondary English instruction, Mi'kmaq language and integration methods, Noline views the integration of literacy through comparative linguistics, personal experiences and traditional teachings as the path to true etuaptmumk. 
Kathy Snow, Noelle Doucette, and Noline Francis

236 | LEARNing Landscapes | Spring 2020, Vol. 13 